\title{
Rail Expansion Devices Monitored by FBG Sensors on an Urban Railway Viaduct
}

\author{
Weilai $\mathrm{LI}^{1^{*}}$, Jin PANG ${ }^{2}$, Xiaoshan $\mathrm{LU}^{2}$, and Jie $\mathrm{LIU}^{2}$ \\ ${ }^{1}$ National Engineering Lab of Fiber Optic Sensing Technology, Wuhan University of Technology, 122 Luoshi Road, \\ Wuhan, 430070, China \\ ${ }^{2}$ Key Lab of Fiber Optic Sensing Technology and Information Processing, Wuhan University of Technology, 122 Luoshi \\ Road, Wuhan, 430070, China \\ *Corresponding author: Weilai LI_ E-mail: 1wl@whut.edu.cn
}

\begin{abstract}
The fiber Bragg grating (FBG) sensing technology was used to monitor the situation of a crevice of the continuous beam joint and rails near rail expansion devices on a viaduct of the urban railway. The monitoring items consisted of the rail temperature, rail displacement, viaduct beam displacement, and strain of sliding rail in the rail expansion device section. The strain sensor was a prefabricate FBG strain gauge, the displacement sensor with different scales used an FBG stress ring, and the FBG of the temperature sensor was pre-drawn and fixed in a metal tube. Compensation sensors were used to balance environmental temperature changes. All FBGs were suspended adhered, therefore the chirped phenomenon of the FBG reflection peak was avoided, and the measurement accuracy was improved. The monitoring results matched to the manual test and theoretical estimation.
\end{abstract}

Keywords: Fiber Bragg grating, urban rail, viaduct, rail expansion device, monitor

Citation: Weilai LI, Jin PANG, Xiaoshan LU, and Jie LIU, "Rail Expansion Devices Monitored by FBG Sensors on an Urban Railway Viaduct," Photonic Sensors, 2014, 4(2): 173-179.

\section{Introduction}

Because of the limitation of the construction cost, viaducts are always adopted when an urban railway is constructed in suburbs. When the line crosses a river or road, the continuous beam structure is used to increase its span. Compared with the simply supported beam, the continuous beam performs litter deformation under the train load, and its additional force of flexure is not big. However, under the influence of the environment temperature, its temperature force of expanding or contracting is bigger. It causes rail axial stress increasing and creeping. To reduce this temperature force, the rail expansion device is installed near the continuous beam in many railway lines [1]. But the rail expansion device has its own safety problems, such as the complicated stress state, large displacement, even pushing against rail fasteners to be damaged. So it is necessary to monitor the continuous beam and rail expansion device online. One of the most significant characteristics of the fiber Bragg grating (FBG) sensor is the long-term stability, since it is of corrosion resistance and zero drift immunity. The FBG sensing technology is of good accuracy, moisture-proof, and anti-electromagnetic interference in the engineering application [2], and it could therefore meet the measuring demand under

Received: 29 December 2013 / Revised version: 8 March 2014

(C) The Author(s) 2014. This article is published with open access at Springerlink.com

DOI: $10.1007 / \mathrm{s} 13320-014-0163-6$

Article type: Regular 
the harsh environment of railway viaducts.

\section{Monitoring system}

The continuous beam of this viaduct was a structure of $40 \mathrm{~m}+68 \mathrm{~m}+40 \mathrm{~m}$ pre-stressed concrete rigid frame, and there were four rail expansion devices installed on the simply supported beam near the joint of the continuous beam. The viaduct and FBG monitoring system are shown in Fig. 1. At each outside rail of the upward and downward lines, there was a symmetrically installed temperature sensor, at Point 1 or 5 . Two sensors detecting the displacement between the rail and sleeper slab were arranged at Points 3 and 7. Two sensors detecting the displacement of the crevice between the continuous beam and simply supported beam were at Points 4 and 8. Two strain sensors detecting the sliding rails of rail expansion devices were at Points $\mathrm{J} 1$ and $\mathrm{J} 2$.
Another two strain sensors detecting the stress of the rails were at Points 2 and 6 .

In Fig. 1, each 4-digit following sensor number is sensor's wavelength value, and their unit is nanometer. Reference gratings were used to compensate the interference caused by the environmental temperature. The grating part of all FBGs was suspended to avoid the Bragg reflection peak to be chirped [3] for improving the measuring precision. These sensors converted measuring physical quantities into the light wavelength signal and then transmitted them by the armored cable to a control room at the nearby station. By a device of photoelectric conversion and demodulation, the wavelength shifts of all FBGs were obtained. An industrial computer processed all wavelength data into required physical quantities back and sent them into Internet for visiting by operators.

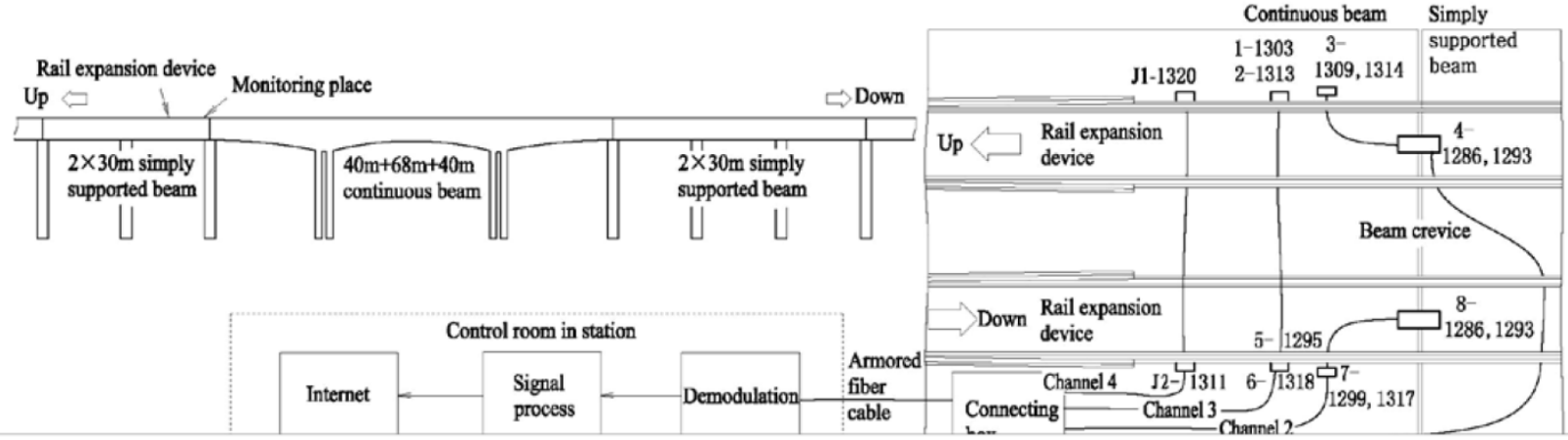

Fig. 1 Monitoring system and sensor configuration.

\section{FBG sensors}

The feature of temperature sensing of a bare FBG was $1{ }^{\circ} \mathrm{C}$ corresponding to the $10-\mathrm{pm}$ wavelength shift. While its both ends were pre-drawn and adhered to a metal tube, its temperature sensitivity was sensitized to $1{ }^{\circ} \mathrm{C}$ for the $25-\mathrm{pm}$ wavelength shift. In this system, metal tube temperature sensors were used. There was no external force loaded on the tube, except temperature expansion. The tiny expansion difference between glue and steel was ignored. Their measuring range was from $-40{ }^{\circ} \mathrm{C}$ to $100{ }^{\circ} \mathrm{C}$, and the on-site measuring precision was $0.5{ }^{\circ} \mathrm{C}$. Figure 2

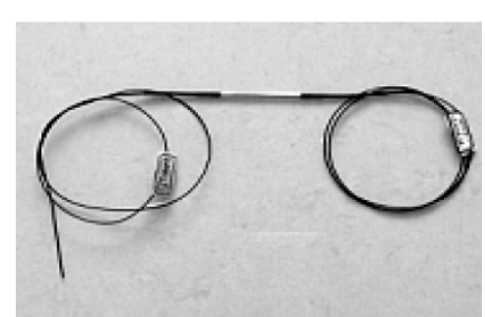

(a)

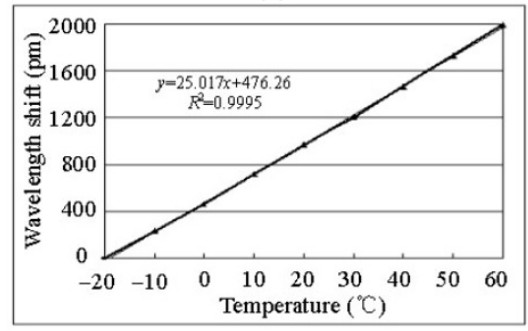

(b)

Fig. 2 FBG temperature sensor. 
shows the shape of the system temperature sensor. In the application, the FBG temperature sensor was placed in the rail strain box as shown in Fig.3(a). Figure 2(b) shows the calibration results on the simulation environment temperature box at $-20{ }^{\circ} \mathrm{C}$ and $60{ }^{\circ} \mathrm{C}$. The measuring range was from $-60{ }^{\circ} \mathrm{C}$ to $120{ }^{\circ} \mathrm{C}$, and at the scene, the temperature measurement precision was $0.5{ }^{\circ} \mathrm{C}$.

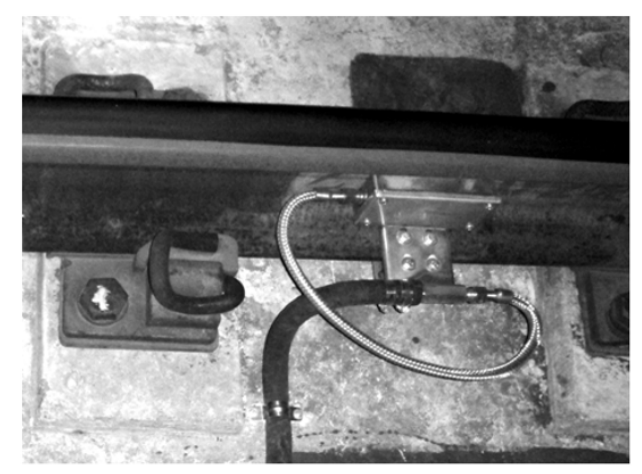

(a)

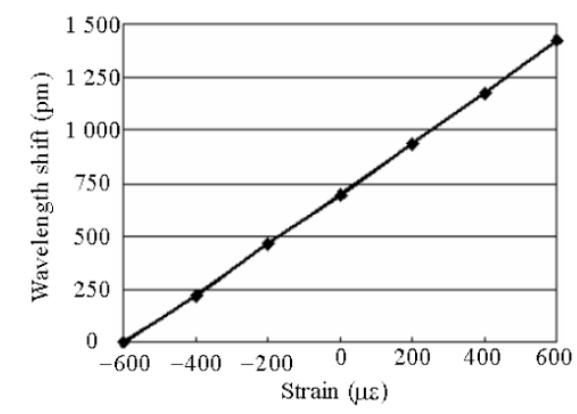

(b)

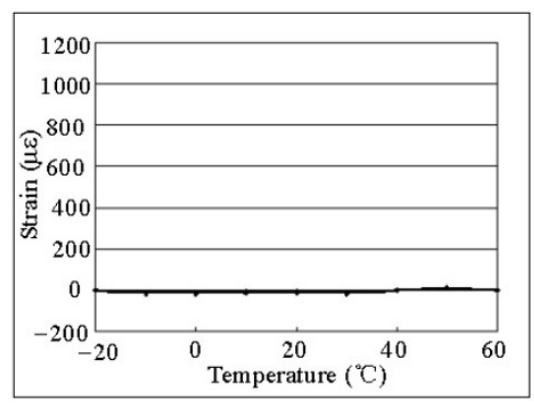

(c)

Fig. 3 FBG strain sensor holding on the rail (a), strain-wavelength curve (b), and temperature compensation result (c).

The strain sensor was a piece of the metal gauge with an FBG on it. Its special feature made the rigidity in its detecting direction weak, and the FBG was also suspended, pre-drawn, and adhered to its non-grating parts. The FBG gauge was adhered by steel structure glue along with the neutral axis of the rail. In this direction, non axial stress was minimized. Figure 3(a) shows a box holding strain sensor and a temperature sensor, and bolts and clamping blocks sandwiched the rail to protect the optical fiber. Drilling and welding on the rail was avoided. Figure 3(b) shows a wavelength- strain curve of the FBG strain gauge by calibration. Its measuring range was from $-1500 \mu \varepsilon$ to $1500 \mu \varepsilon$, and the measuring precision was $+/-3 \mu \varepsilon$. In the application, the monitoring data were processed as stress (MPa).

The core of the FBG displacement sensor was a deforming ring [4], as shown in Fig. 4.
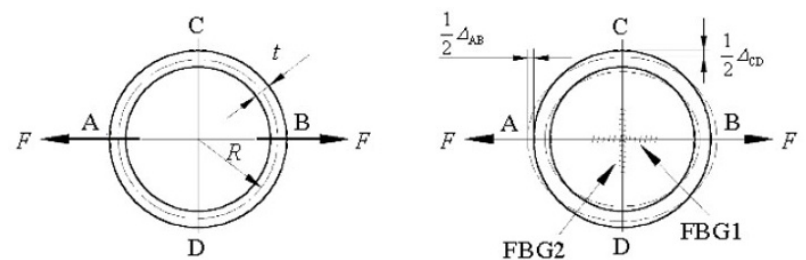

Fig. 4 Deforming ring of the displacement sensor.

Two FBGs with different wavelengths were fixed across. FBG1 was on $\mathrm{AB}$, and $\mathrm{FBG} 2$ was on $\mathrm{CD}$. In the $\mathrm{AB}$ direction, putting a force $F$, the ring was stretched, and a positive wavelength shift was produced. At same time in the CD direction, FBG2 was compressed, and its wavelength shift was negative.

The displacement variation between the two points is as follows:

$$
\Delta_{\mathrm{AB}}=\frac{\pi^{2}-8}{4 \pi} \frac{F R^{3}}{E I}
$$

where $F$ is a pair of external forces applied, $E$ is the young's modulus of the ring material, $E=2 \times 10^{11} \mathrm{~Pa}$, $R$ is the central radius of the circle, and $I$ is the moment of inertia, which can be obtained by the formula $I=h t 3 / 12$ (in which $h$ is the height of the ring, and $t$ is the radial thickness of the ring).

Fiber Bragg grating shape variables are as follows:

$$
\varepsilon=\frac{\Delta_{\mathrm{AB}}}{2 R}=\frac{\left(\pi^{2}-8\right)}{8 \pi} \frac{F R^{2}}{E I} .
$$

The strains of A and B could be got by the mechanical formula. $\Delta_{\mathrm{AB}}$ is a deformation between 
$\mathrm{A}$ and $\mathrm{B}$, because of ring's symmetrical shape, $\Delta_{\mathrm{CD}}=$ $-\Delta_{\mathrm{AB}}$. The FBG displacement sensor consisted of a deforming ring, a tensile spring, a rod, and a shell. To fix Point $\mathrm{A}$ of the deforming ring at the shell, through the tensile spring and rod, Point B detected the displacement. Figure 5 also shows the site instillation of the FBG rail displacement sensor and beam displacement sensor.

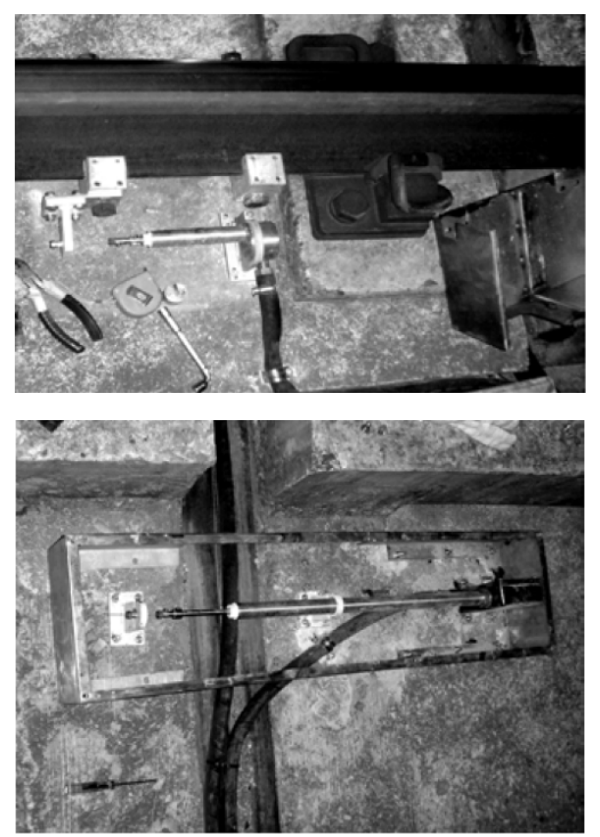

Fig. 5 Uncovered FBG rail displacement sensor and uncovered beam displacement sensor.

For the rail displacement sensor, the detecting range was $0-50 \mathrm{~mm}$, while the beam displacement sensor was $0-200 \mathrm{~mm}$. The sizes of their springs were different, but at full scale, both their tensile forces made the deforming ring produce $1500-\mu \varepsilon$ strain. Figs. 6(a) and 6(b) show calibration results of two kinds of sensors. The thin solid line refers to the tensile FBG1 wavelength responding to the displacement. The dashed line refers to compressing FBG2. To add two absolute values of them, the summation doubles their wavelength response and sensibility shown as the thick lines. It obviously eliminates the shift caused by the environment temperature. It can be seen in Fig. 6 that the sensitivity of the rail displacement sensor is higher than the beam sensor. For the former, the 1-mm displacement responds to the 52-pm wavelength shift, while for the latter, $1 \mathrm{~mm}$ is for $16 \mathrm{pm}$.

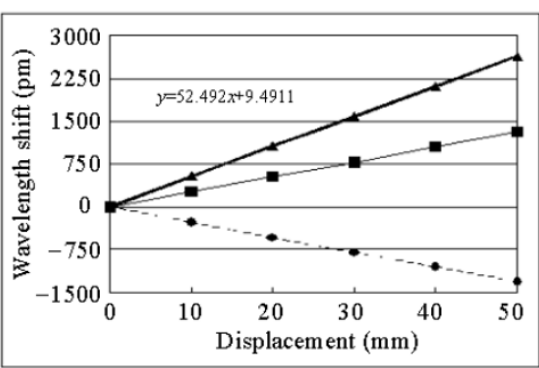

(a)

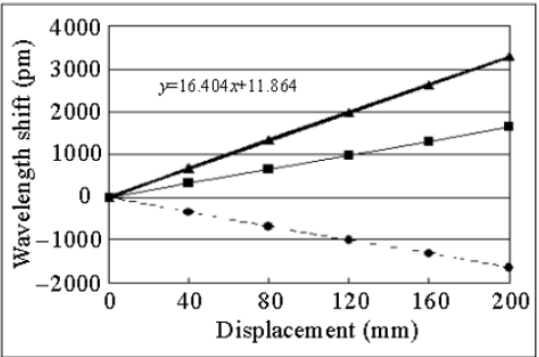

(b)

Fig. 6 Calibration of the rail (a) and beam crevice (b) displacement sensors.

To fix the rob of these displacement sensors at a half range, then put them into an environmental test chamber, and record the temperature in every $10{ }^{\circ} \mathrm{C}$, from $-20{ }^{\circ} \mathrm{C}$ to $60{ }^{\circ} \mathrm{C}$, their temperature characteristics of FBG1 and FBG2 were obtained, as shown in Fig.7(a). The features of two FBGs were the same, so two curves are overlapped. By

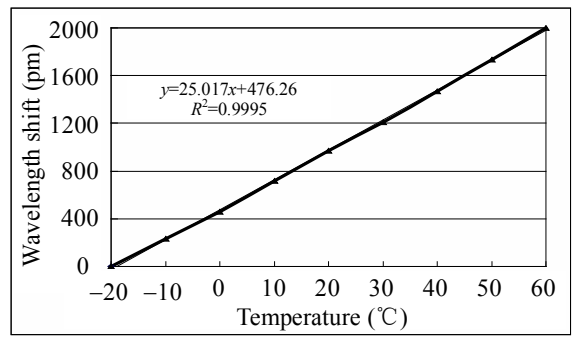

(a)

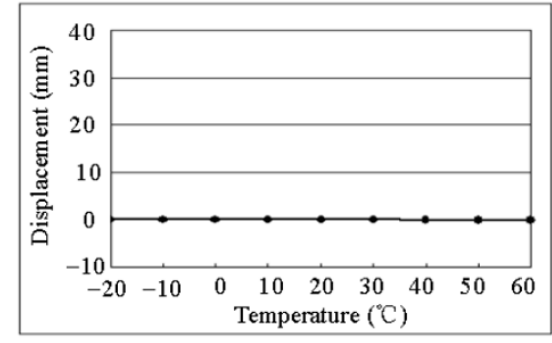

(b)

Fig. 7 Temperature characteristic of the deforming ring (a) and temperature characteristic of two-FBG after compensation (b). 
subtracting them, the results are shown in Fig. 7(b). When the change in the temperature was $80{ }^{\circ} \mathrm{C}$, the displacement error was only $0.3 \mathrm{~mm}$.

\section{Result analysis}

The monitoring system collected measuring data every 20 minutes. It has experienced local high temperature and low temperature since it was installed. Because this viaduct is in a subtropical city, a 3-day average rail temperature at detecting point 1 was as high as $36{ }^{\circ} \mathrm{C}$, as shown in Fig. 8(a). In the period of low temperature, a 3-day average temperature was $20{ }^{\circ} \mathrm{C}$, illustrated as Fig. $8($ b). The monitoring result at the opposite rail temperature sensor point 5 was the same.

The top curve of Fig. 9 was taken from the rail creeping displacement monitoring point 7 on the outside of the downward rail. From 0 on the 15 th of September that was installing time to the 1 st of January, the rail crept to $66 \mathrm{~mm}$. The creeping direction was in the downward direction. The nether curve of Fig. 9 was taken from the upward rail point 3. At the same period, that rail crept from 0 to $57 \mathrm{~mm}$, and the displacement was also in the downward direction.

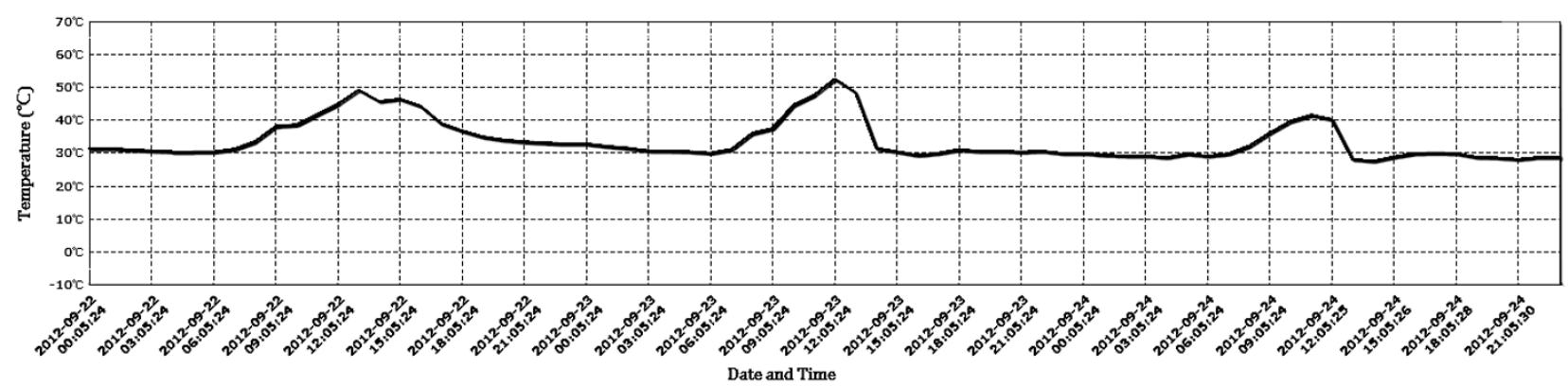

(a)

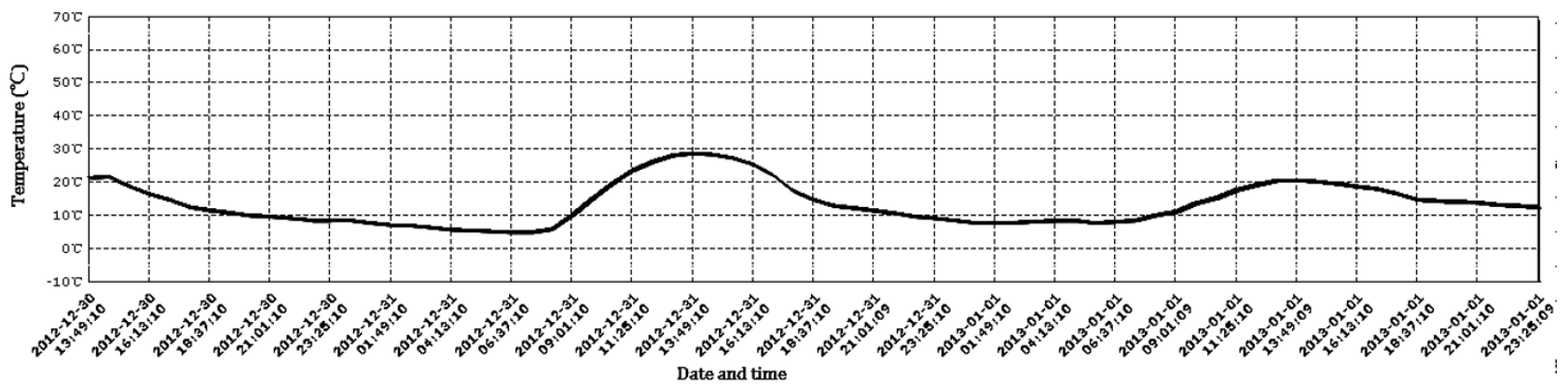

(b)

Fig. 8 Rail temperature.

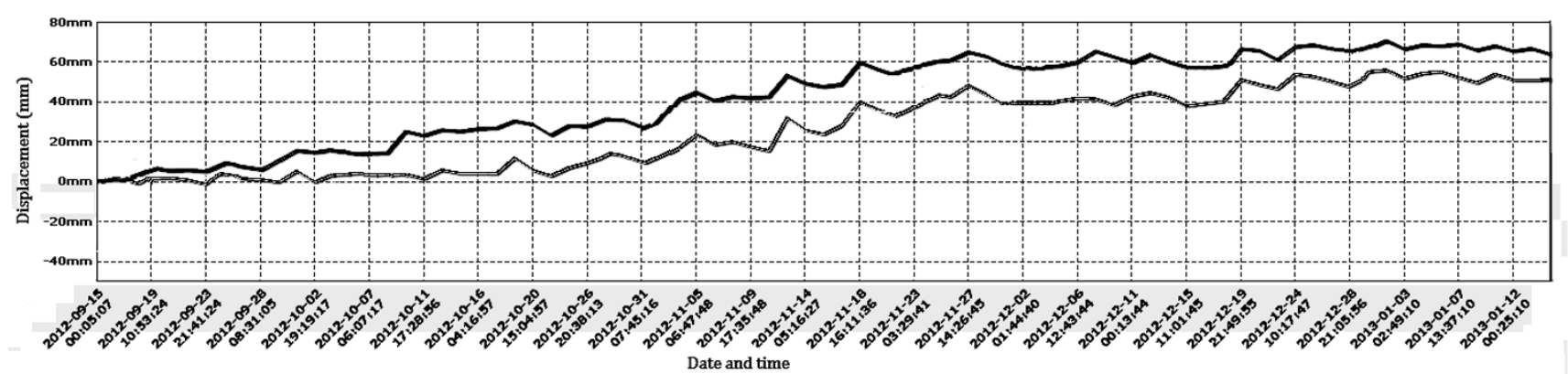

Fig. 9 Curves of the rail displacement.

At the downward side monitoring point 8 , the beam crevice displacement curve is shown as the top curve of Fig. 10. It developed from 0 during high temperature to $57 \mathrm{~mm}$ during low temperature, and the beam crevice became wider. The other displacement of the beam crevice from the 
monitoring point 4 is shown as the nether curve of Fig. 10. From 0 to $47 \mathrm{~mm}$, the crevice developed widely. The displacements of the rails and beam crevice were associated with the seasonal temperature change, but they were independent of the daily temperature change, and all kinds of displacements have been checked by manual, and the error was only $1 \mathrm{~mm}-2 \mathrm{~mm}$.

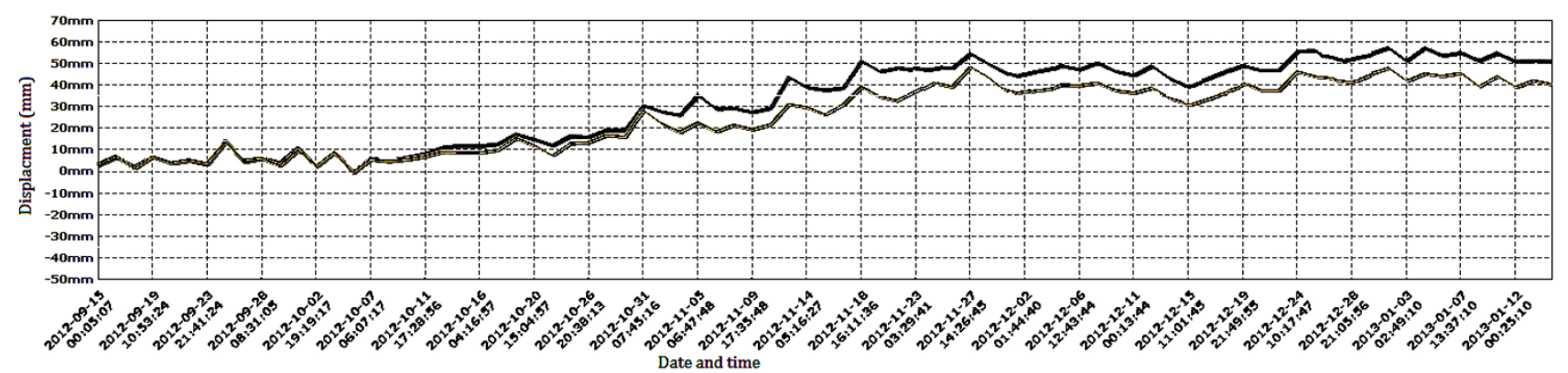

Fig. 10 Beam crevice displacement.

The curve of the axial rail stress was different 2 developed from $-30 \mathrm{MPa}-0 \mathrm{MPa}$ during high temperature to $10 \mathrm{MPa}-40 \mathrm{MPa}$ during low temperature, shown as the top curve of Fig. 11. For the stress of the sliding rail at Point $\mathrm{J} 1$, its change was smaller than the former, shown as the nether curve of Fig. 11. The curves of the monitoring point 2 and monitoring point $\mathrm{J} 2$ of the downward rail were the same as those in Fig. 11.

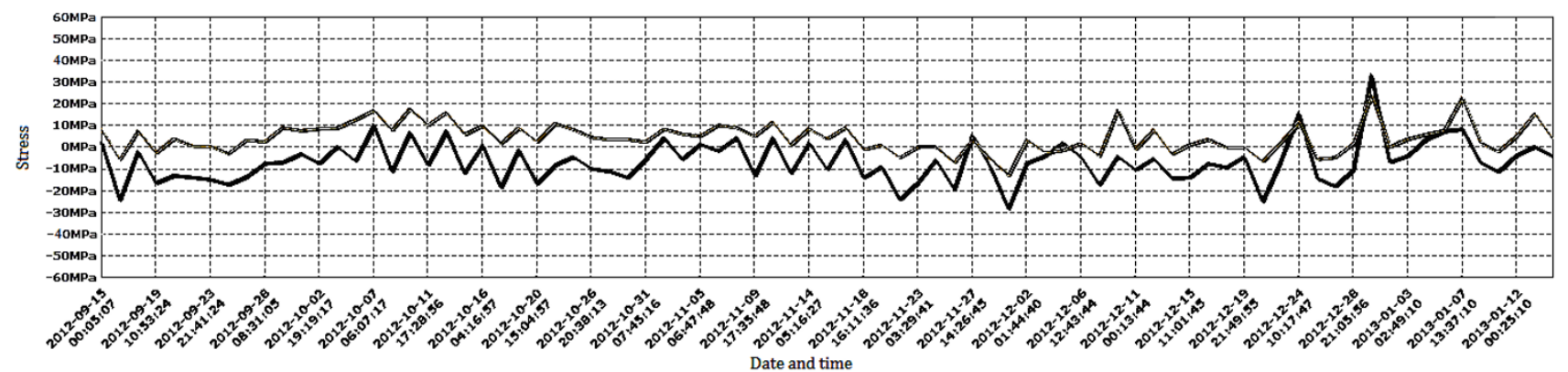

Fig. 11 Rail stress.

According to a national standard [5], when the environmental temperature changes, the expanding value of a rail expansion device can be calculated as follows:

$$
\Delta l=\frac{\left(P_{t b}-P_{R}\right)}{2 E F Q}
$$

where $P_{t b}$ is the seamless track rail temperature force. $P_{R}$ is the rail joint resistance, $E$ is the rail steel elastic modulus, $F$ is the rail cross-sectional area, and $Q$ is the line longitudinal resistance.

Taking the measured stress and rail temperature as known conditions, the rail expanding displacement value $\Delta l$ was calculated as same as the displacement online obtained by this monitoring system.

\section{Conclusions}

Due to the enclosed operation, the persons maintaining the urban railway maintenance are difficult to check and measure manually the temperature, displacement, and stress of the rail structure. This system takes advantage of the fiber optical sensing technology to do continuously online monitoring. The methods and accurate results are 
helpful for the large-scale viaduct construction of both the urban and high-speed railways in the country. This application is also helpful to change the situation of the fiber optical sensing technology that is paid more attention on the theoretical research, but less on engineering application. Because of constraints in installation, the beam displacement sensors were not installed between the beam and pier to measure an absolute displacement of the viaduct.

Open Access This article is distributed under the terms of the Creative Commons Attribution License which permits any use, distribution, and reproduction in any medium, provided the original author(s) and source are credited.

\section{References}

[1] C. Tian, M. Yin, and P. Wang, "Some thoughts about the continuous welded rail using rail expansion device," Railway Engineering, 2006, 2006(2): 59-65.

[2] D. Jiang and W. He, "Review of application for FBG sensors," Optoelectronics \& Lasers, 2002, 1(4): $420-426$.

[3] X. Zhou, L. Liang, and D. Jiang, "Research of strain transferring rules for stickup FBG sensors," Sensors World, 2007(7), 14-18.

[4] W. Li, Y. Zhang, Q. Wang, J. Pan, J. Liu, and C. Zhou, "Displacement monitor with FBG deforming ring and its application in high speed railway," in Proc. SPIE, vol. 8421, pp. 8421AU-1-8421AU-4, 2012.

[5] Standard of former China Ministry of Railway, "Calculation of long welding seamless rail creeping displacement on railway bridge," 2003: 7 . 